\title{
Endoscopic ultrasound-guided transmural drainage for subphrenic abscess: report of two cases and a literature review
}

\author{
Shinichi Morita ${ }^{1 *} \mathbb{D}$, Kenya Kamimura², Takeshi Suda ${ }^{1}$, Chiyumi Oda', Takahiro Hoshi ${ }^{1}$, Tsutomu Kanefuji ${ }^{1}$,
} Kazuyoshi Yagi ${ }^{1}$ and Shuji Terai ${ }^{2}$

\begin{abstract}
Background: An intra-abdominal abscess can sometimes become serious and difficult to treat. The current standard treatment strategy for intra-abdominal abscess is percutaneous imaging-guided drainage. However, in cases of subphrenic abscess, it is important to avoid passing the drainage route through the thoracic cavity, as this can lead to respiratory complications. The spread of intervention techniques involving endoscopic ultrasonography (EUS) has made it possible to perform drainage via the transmural route.

Case presentation: We describe two cases of subphrenic abscess that occurred after intra-abdominal surgery. Both were treated successfully by EUS-guided transmural drainage (EUS-TD) without severe complications. Our experience of these cases and a review of the literature suggest that the drainage catheters should be placed both internally and externally together into the abscess cavity. In previous cases there were no adverse events except for one case of mediastinitis and pneumothorax resulting from transesophageal drainage. Therefore, we consider that the transesophageal route should be avoided if possible.

Conclusions: Although further studies are necessary, our present two cases and a literature review suggest that EUS-TD is feasible and effective for subphrenic abscess, and not inferior to other treatments. We anticipate that this report will be of help to physicians when considering the drainage procedure for this condition. As there have been no comparative studies to date, a prospective study involving a large number of patients will be necessary to determine the therapeutic options for such cases.
\end{abstract}

Keywords: Endoscopic ultrasound-guided transmural drainage, Subphrenic abscess, Intra-abdominal abscess, EUS

\section{Background}

Intra-abdominal abscess is a severe infectious condition refractory to cure with antibiotic monotherapy $[1,2]$. Therefore, the basic treatment strategy has been percutaneous imaging-guided drainage [3, 4]. However, in cases of subphrenic abscess [5], the lesion is surrounded by other organs such as the lungs, liver and intestines, sometimes making it difficult to secure a safe drainage route percutaneously, and surgical drainage may therefore be needed, even though it is invasive $[6,7]$.

\footnotetext{
* Correspondence: m0riz0u@extra.ocn.ne.jp

${ }^{1}$ Department of Gastroenterology and Hepatology, Uonuma institute of

Community Medicine Niigata University Hospital, 4132 Urasa,

Minamiuonuma City, Niigata 949-7302, Japan

Full list of author information is available at the end of the article
}

Recently, the development of endoscopic ultrasonography (EUS) intervention techniques has made it possible to perform puncture and drainage via the transmural route for the deeper part of the abscess, where percutaneous treatment has been difficult [8-13]. Here we report two cases of subphrenic abscess that were treated successfully with EUS-guided transmural drainage (EUS-TD). With a view to developing a safe and effective drainage procedure, we reviewed 14 reported cases of subphrenic abscess treated with EUS-TD in addition to our own two cases. We anticipated that the information in this report would be of help to physicians for safer and more effective management of subphrenic abscesses.

(c) The Author(s). 2018 Open Access This article is distributed under the terms of the Creative Commons Attribution 4.0 International License (http://creativecommons.org/licenses/by/4.0/), which permits unrestricted use, distribution, and reproduction in any medium, provided you give appropriate credit to the original author(s) and the source, provide a link to the Creative Commons license, and indicate if changes were made. The Creative Commons Public Domain Dedication waiver (http://creativecommons.org/publicdomain/zero/1.0/) applies to the data made available in this article, unless otherwise stated. 


\section{Case presentation}

\section{Case 1}

A 66-year-old Japanese man underwent laparoscopic partial resection for sigmoid colon cancer. His progress after surgery was smooth and he was discharged on the 7th postoperative day. However, 17 days after surgery he developed a high-grade fever of $40{ }^{\circ} \mathrm{C}$ and upper abdominal pain, necessitating readmission to our hospital. Laboratory examinations demonstrated a significant increase in the white blood cell count to $16,000 / \mu \mathrm{L}$ and a C-reactive protein level of $19.2 \mathrm{mg} / \mathrm{dL}$. Contrast-enhanced computed tomography (CT) revealed an encapsulated mass of accumulated fluid $90 \mathrm{~mm}$ in diameter adjacent to the upper part of the stomach (Fig. 1a, b). On the basis of the symptoms, and the findings of laboratory and imaging examinations, a diagnosis of left-sided subphrenic abscess was made. Tazobactam/piperacillin, a broad-spectrum antibiotic, was administered three times daily ( $4.5 \mathrm{~g} /$ day) for 4 days, but little improvement was observed. Therefore, a decision was made to perform drainage of the abscess. As the percutaneous drainage line showed an intrathoracic pathway, and a clear image was obtained via the stomach by EUS, EUS-TD was selected as the drainage method.

A linear-array echoendoscope (GF-UCT260 and UE-ME2 US system; Olympus Medical, Tokyo, Japan) was employed for the procedure and EUS-images were carefully checked to examine whether the abscess wall was well matured. It showed that the wall was thick enough and well adherent to the stomach wall. Therefore, following confirmation of a clear puncture line using color Doppler, as standard technical method, a 19-gauge needle (SonoTip pro control ${ }^{\circledR}$, Medi-Globe, Rosenheim, Germany) was inserted into the abscess, confirming aspiration of pus (Fig. 1c). Then, a 0.025-in. guidewire (Visiglide $2^{\mathrm{Tm}}$; Olympus Medical) was inserted through the needle followed by insertion of a cautery catheter (Cyst-Gastro set ${ }^{\circledR}$; Century Medical, Seoul, Korea) into the cavity, creating a ostomy to the abscess from the stomach under endosonographic and fluoroscopic guidance. After dilation of this ostomy using an 6-mm-diameter balloon catheter (ZARA ${ }^{\oplus}$; Century Medical), a 5-cm-long 7F double pigtail plastic stent (Advanix ${ }^{\oplus}$; Boston Scientific, Marlborough, USA) and 6F naso-abscess catheter (Quick Place $\mathrm{V}^{\mathrm{s}}$; Olympus Medical) were inserted to drain the pus either into the stomach and extracorporeally (Fig. 1d). Culture of the pus demonstrated infection with Klebsiella pneumoniae, and on the day after drainage the high fever and abdominal pain were improved. As the waste liquid was high-viscosity pus, the naso-abscess catheter was irrigated with physiological saline to avoid any obstruction. Fluoroscopic imaging with contrast medium enhancement from the naso-abscess catheter demonstrated shrinkage of the abscess cavity and no leakage at the anastomosis of the transected colon (Fig. 1e). Therefore, the naso-abscess catheter was removed after 7 days and disappearance of the abscess was confirmed 1 month later (Fig. 1f), followed by the removal of the pigtail stent. The post-procedure course was uneventful and adjuvant chemotherapy was performed successfully.
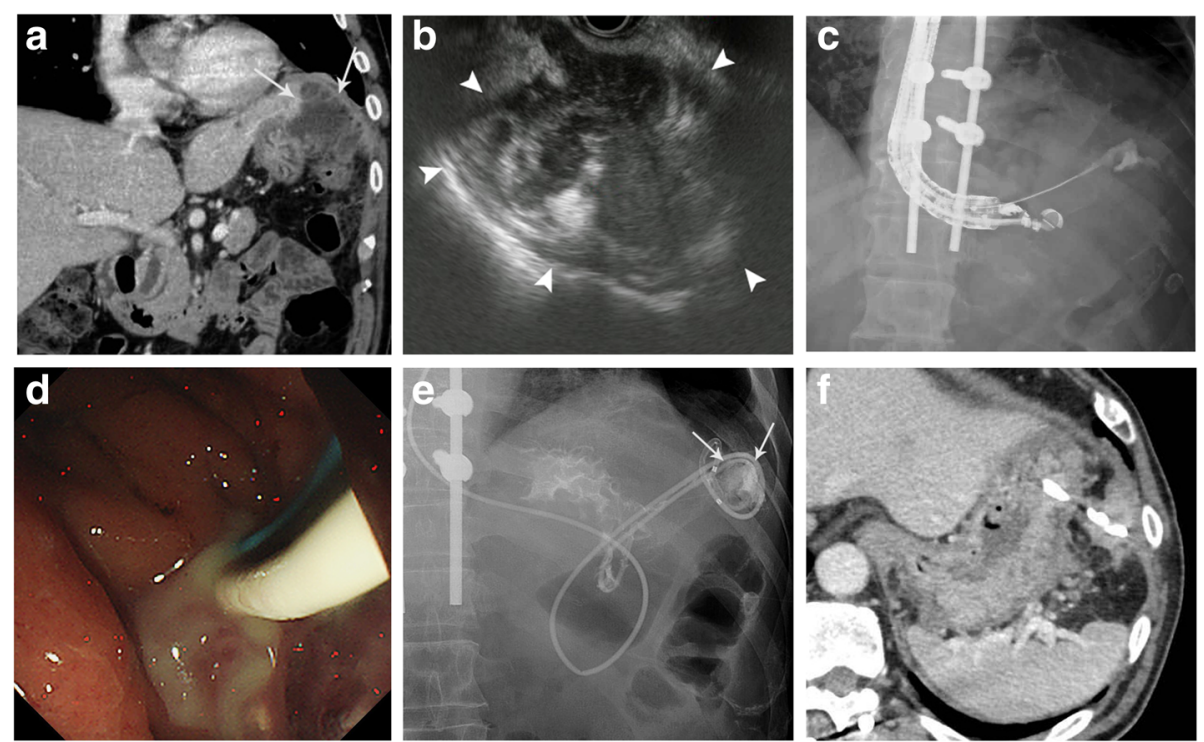

Fig. 1 a Contrast-enhanced computed tomography (CT) shows fluid collection (arrows) in the left subphrenic area adjacent to the fornix of the stomach. $\mathbf{b}$ Endoscopic ultrasound shows irregular fluid collection (arrowheads). c Fluoroscopic image shows a 19-gauge needle inserted into the abscess cavity. $\mathbf{d}$ Endoscopic image shows much viscous pus extruding into the stomach through the stents. e Fluoroscopic image with contrast medium enhancement via the naso-abscess external catheter shows shrinkage of the abscess cavity (arrows) and no leakage from the anastomosis of the transected colon. $\mathbf{f}$ CT reveals that the drainage stent and that the drained abscess cavity became shrank 
To date, no recurrence of the abscess or metastases from the colon cancer has been observed. The clinical course including changes in temperature and the serum C-reactive protein level are shown in Fig. 2.

\section{Case 2}

A 57-year-old Japanese woman with diabetes mellitus underwent right hemicolectomy for cancer of the ascending colon. She suffered from a persistent high-grade fever of $40{ }^{\circ} \mathrm{C}$ for 14 days after surgery, and despite antbiotic therapy she showed no improvement. Laboratory examinations demonstrated a significant increase in the white blood cell count to $13,300 / \mu \mathrm{L}$ and the $\mathrm{C}$-reactive protein level to $14.6 \mathrm{mg} / \mathrm{dL}$. CT imaging revealed a mass of accumulated fluid $70 \mathrm{~mm}$ in diameter containing gas, suggesting formation of an abscess adjacent to the upper part of the stomach (Fig. 3a). Based on these findings, a diagnosis of subphrenic abscess was made and cefmetazole was administered twice daily ( 2 g/day) for 7 days. However, as the effect was insufficient, the antibiotic was changed to meropenem, a broad-spectrum antibiotic, twice daily ( $2 \mathrm{~g} /$ day) for 5 days. As this in turn proved ineffective, EUS-TD was performed because no appropriate percutaneous puncture line was available. EUS-image showed the maturation of abscess wall with its thickness and adherence to the stomach wall. Therefore, a 5-cm-long $7 \mathrm{~F}$ double pigtail plastic stent and a $6 \mathrm{~F}$ naso-abscess catheter were placed into the abscess cavity (Fig. 3b, c, d), as described for Case 1. Gram staining and culture of a sample of the aspirate revealed Escherichia coli. On the day after drainage, the high fever ameliorated, and the naso-abscess catheter was irrigated with physiological saline for several days. After 7 days, fluoroscopic imaging with contrast medium enhancement via the naso-abscess catheter showed shrinkage of the abscess cavity (Fig. 3e), and therefore the catheter was removed. CT at 1 month after drainage showed disappearance of the abscess cavities (Fig. 3f), so the pigtail stent was removed with an endoscope. For 7 months thereafter, there was no evidence of abscess recurrence. The clinical course including changes in temperature and the serum $\mathrm{C}$-reactive protein level are shown in Fig. 4.

\section{Discussion and conclusions}

Intra-abdominal abscesses often occur following intraabdominal surgery, trauma, severe enteritis, perforation of the intestine, and acute pancreatitis [5]. If there is any delay in diagnosis and treatment, sepsis may develop, followed by septic shock with a potentially fatal outcome $[1,2]$. Therefore, prompt and adequate treatment is needed. The basic treatment for abscess is drainage, and the first choice of drainage route is percutaneous $[3,4,14]$. Imaging-guided percutaneous abscess drainage has been shown to be effective, and has been a great milestone in the treatment of abscesses [3,14-18]. The modalities used for this procedure have been mostly ultrasonography and computed tomography. Previous reports of percutaneous drainage for intra-abdominal abscess have documented success rates of between $60 \%$ and $92 \%$ [3, 15-18]. In series with high success rates, imaging-guided percutaneous abscess drainage was performed when an available access route could be secured. However, when the abscess cavity is deeply located in the body, it may be difficult to secure a

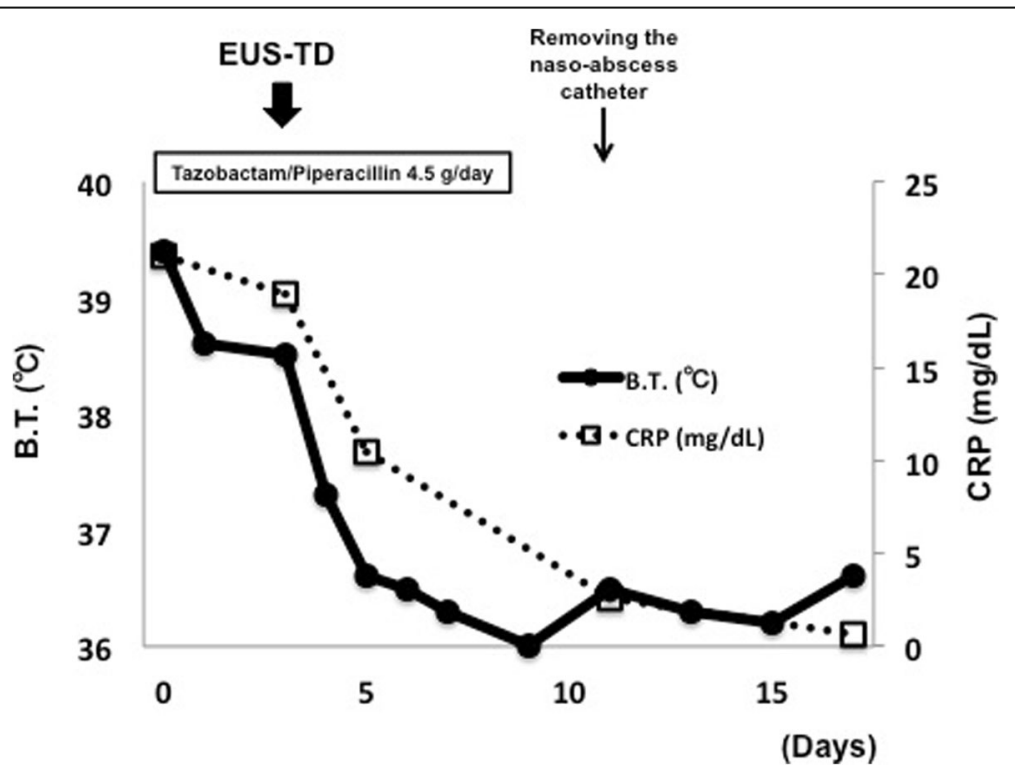

Fig. 2 Changes in body temperature and C-reactive protein level after EUS-TD in Case 1 

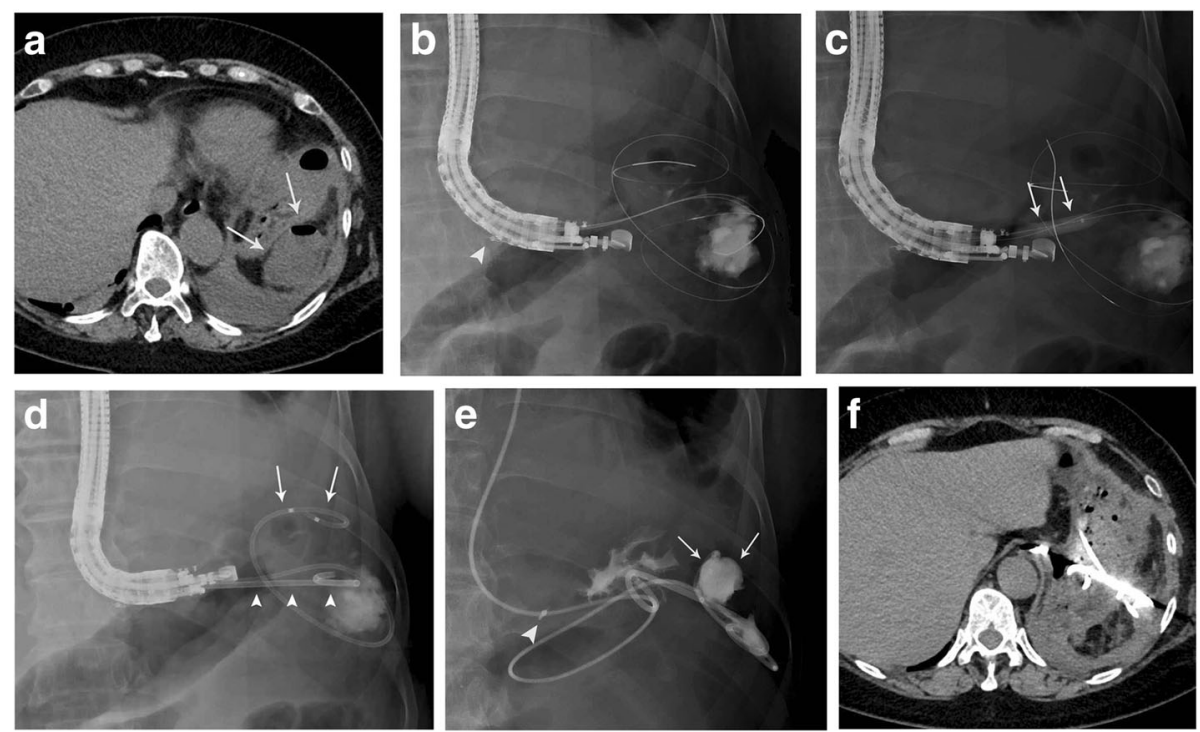

Fig. 3 a CT shows accumulated fluid containing gas (arrows) in the left subphrenic area adjacent to the fornix of the stomach. b Fluoroscopy image shows the guidewires coiling in the abscess cavity. The hemoclip (arrowhead) is placed at the esophageal junction to avoid transesophageal puncture. c Fluoroscopic image shows an 8-mm-diameter balloon catheter (arrows) dilating the ostomy between the stomach and the abscess cavity. d A 5-cm-long 7F double pigtail stent (arrowheads) and a $6 \mathrm{~F}$ naso-abscess catheter (arrows) are placed into the cavity. e Fluoroscopic image with contrast medium enhancement via the naso-abscess external catheter shows shrinkage of the abscess cavity (arrows). The hemoclip (arrowhead) is placed at the esophageal junction. $\mathbf{f}$ CT demonstrates the drainage catheter and stent, and reduction of the abscess cavity

drainage route due to the surrounding organs. Therefore, for such cases, surgical drainage has remained a standard $[3,6,17]$, even though it is highly invasive [3]. With the growing number of elderly patients worldwide, who cannot tolerate highly invasive techniques, there has been a need to develop a less invasive method for drainage of deeply seated abscesses.
Subphrenic abscess is characterized by accumulation of pus or infected fluid in the space between the diaphragm, liver, spleen and intestines [5]. This makes it difficult to puncture while avoiding other organs during intra-abdominal passage, and the drainage route often passes through the thoracic cavity $[7,19,20]$. However, an intrathoracic route carries a risk of severe

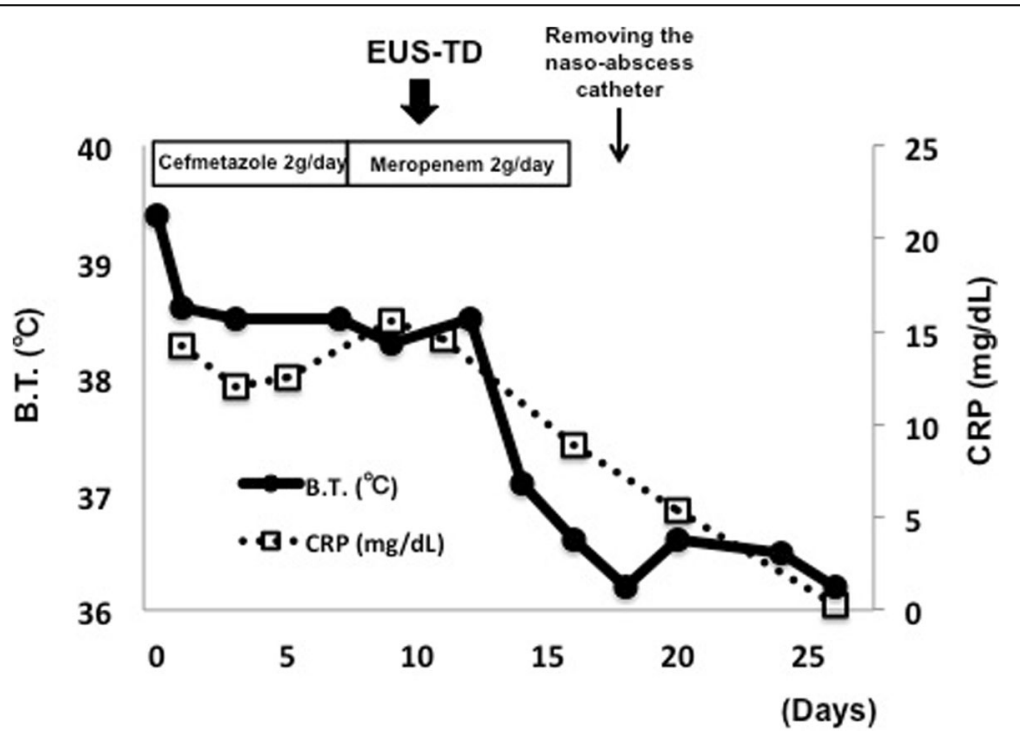

Fig. 4 Changes in body temperature and C-reactive protein level after EUS-TD in Case 2 
complications such as pleural effusion, pneumothorax, pyothorax and mediastinitis [7, 14, 19, 21]. To avoid such complications, the transmural drainage route has been tested with the development of EUS. Since the first report of EUS-TD for pancreatic pseudocyst [22], the technique has been widely used [10, 13, 23-25]. EUS-TD has a number of advantages: 1) excellent visualization of the cavity of the intra-abdominal abscess, even when located deeply; 2) the Doppler mode is able to demonstrate the puncture line, thus avoiding major vessels; 3) real-time US images can be obtained during the procedure. To date, 14 cases, including our case, of subphrenic abscess treated with EUS-TD have been reported, and their details are summarized in Table 1 [8-10, 13, 26-28].

The reported technical and clinical success rates were both $100 \%(14 / 14)$. The drainable abscess location was reported both left and right sides under the diaphragm. However, because of the anatomical location of the stomach, left-sided drainage via the transgastric route is preferable $(92.9 \% ; 13 / 14)$. The organs through which the route passes include not only the stomach but also the esophagus $(14.3 \% ; 2 / 14)$, when the abscess location is adjacent to the intestinal tract.

In both of the present cases, the EUS image was informative to confirm the maturity of the abscess wall and its adherence to the stomach wall in both of our cases. Therefore, especially when a drainage is considered in cases of recently developed abscess, the careful consideration of the conditions and the modification of techniques, devices, including balloon catheters, stent, and etc. are necessary. Drainage methods can be external, internal, or both, as was the case in our patients. Our review indicated that in 50\% (7/14) of cases, both an external naso-abscess drainage catheter and an internal drainage stent were placed. There are several advantages using two such drains. Through a naso-abscess catheter can be aspirated as much of the pus as possible immediately after placement and allow identification of any causative microbial agents. In addition, irrigation of an abscess cavity with a saline can prevent a development of pus obstruction of a catheter by highly viscous pus. It also allows contrast medium enhancement to confirm the size of the abscess cavity and postoperative anastomotic leakage if necessary. An internal drainage stent maintains the transmural drainage tract and allows exchange or addition of new drainage stents. However, naso-abscess catheter placement decreases the patient's quality of life due to nasopharyngeal discomfort. The median period until removal of the naso-abscess catheter was 7 days in the cases we reviewed. Whereas Kassi et al. reported that the median time until removal of the catheter for percutaneous intra-abscess drainage was 13.2 days [4]. On the other hand, $43 \%(6 / 14)$ of presented cases were improved with internal drainage only. Five of these six cases were treated by placement of two 10F DP stents. The wide-lumen stent can secure a sufficient drainage and has reliable long-term patency. Moreover, by means of multiple stenting, pus outflow occurs not only through the lumina of the stents, but also through the space between the stents. If placement a naso-abscess catheter is avoided, it is preferable to place multiple larger-diameter stents. However, it remains to be determined whether internal drainage using multiple stents or external drainage with a naso-abscess catheter is more effective.

Complications of EUS-TD for treatment of pancreatic fluid collections, that can be considered to be similar to that of subphrenic abscess, have been reported in about $10 \%$ of cases, and involve mainly bleeding and perforation [29-33]. Our literature review revealed one complication associated with EUS-TD for subphrenic abscess (1/14), in a patient treated via the transesophageal drainage route who developed mediastinitis and pneumothorax. These complications have also been reported for EUS-fine needle aspiration and EUS-TD via the esophagus via the transthoracic route [10, 34-36]. Therefore, the transesophageal route should be avoided if possible, and some form of percutaneous or surgical procedure may have to be considered for such cases. We have recently reported a useful technique of clip anchoring at the esophagogastric junction [37]. Hemoclips were placed at the esophageal junction in advance, and the drainage catheters were inserted into the abscess cavity under fluoroscopic observation at a point distal to the clips. This technique can help to avoid intrathoracic passage.

Our review indicated that $42.9 \%(6 / 14)$ of patients were over 60 years old. As the number of elderly patients is increasing worldwide, less invasive and more effective methods for abscess drainage are needed. Recently in the EUS-intervention field, reports of a use of lumen apposing metal stents (LAMS) have been increasing $[38,39]$ and such stents have actually been used for drainage of pancreatic fluid collections and abdominopelvic abscesses [34]. The wide lumen allows effective drainage and the characteristic stent edges prevent leakage into the abdominal cavity and stent migration. It is expected that this type of stent may be placed more safely, and allow more effective drainage than an ordinary stent. On the other hand, there have been some reports of severe adverse events such as perforation and massive bleeding related to EUSTD with LAMS for pancreatic walled-off necrosis [33]. Therefore, further prospective studies are essential to prove its usefulness. Our present experiences and literature review indicate that EUS-TD for subphrenic abscess is feasible and effective. It is anticipated that the information summarized in this article may be of help to physicians when considering the drainage procedure for this 


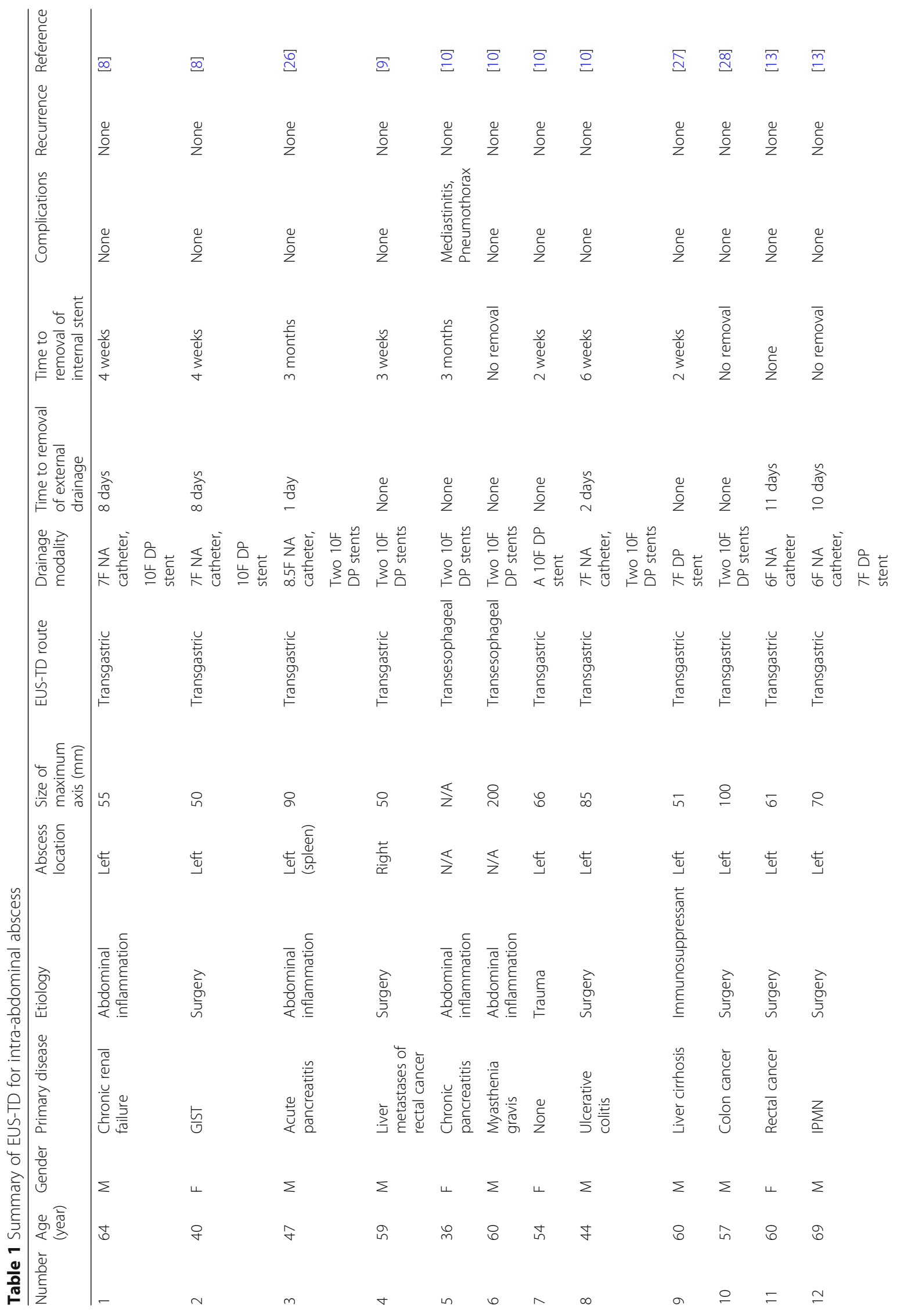


Morita et al. BMC Gastroenterology (2018) 18:55

Page 7 of 9

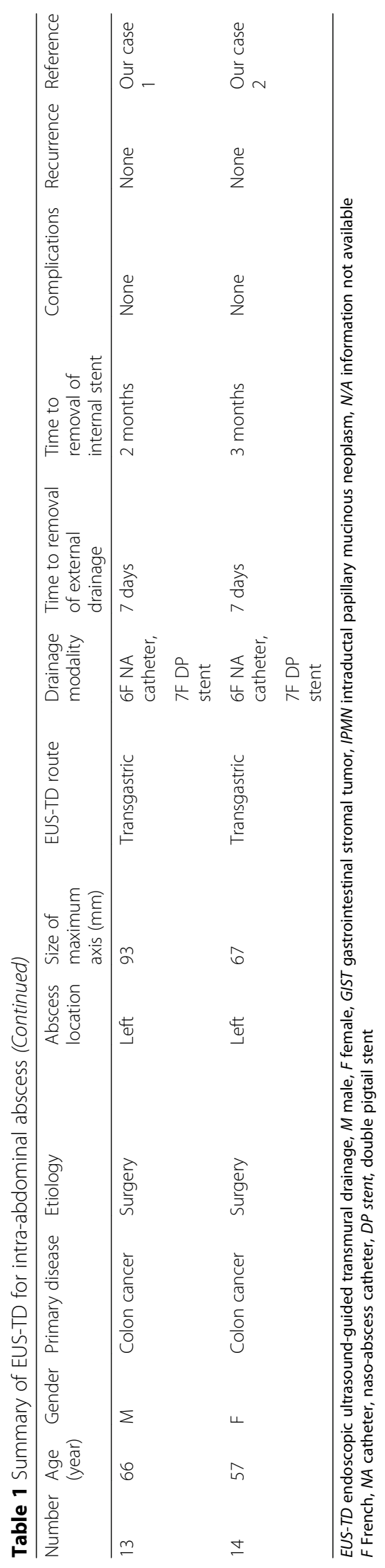


condition. As there have been no comparative studies to date, a prospective study involving a large number of patients will be necessary to determine the therapeutic options for individual cases.

\section{Abbreviations}

BT: body temperature; CRP: C-reactive protein; CT: computed tomography; DP stent: double pigtail stent; EUS: Endoscopic ultrasonography; EUS-TD: Endoscopic ultrasound-guided transmural drainage; F: French; LAMS: lumen apposing metal stent; NA catheter: naso-abscess catheter

\section{Acknowledgements}

We would like to thank Douglas for English language editing and Publication Support.

\section{Authors' contributions}

MS wrote manuscript. MS, HT and KT treated patients. KK, OC, YK, ST and TS provided clinical advice and revised the paper. All authors approved the final manuscript for publication.

\section{Ethics approval and consent to participate}

This study was reviewed and approved by the institutional Human Investigation Committee of the Unuma institute of Community Medicine Niigata University Hospital (Approval \#2017-052).

\section{Consent for publication}

Written informed consent was obtained from all patients in accordance with the Helsinki declaration for publication of this case report and accompanying images. All patients' data have been appropriately de-identified.

\section{Competing interests}

The authors declare that they do not have a current financial arrangement or affiliation with any organization that may have a direct interest in their work.

\section{Publisher's Note}

Springer Nature remains neutral with regard to jurisdictional claims in published maps and institutional affiliations.

\section{Author details \\ 'Department of Gastroenterology and Hepatology, Uonuma institute of Community Medicine Niigata University Hospital, 4132 Urasa, Minamiuonuma City, Niigata 949-7302, Japan. ${ }^{2}$ Division of Gastroenterology and Hepatology, Graduate School of Medical and Dental Sciences, Niigata University, 1-757 Asahimachido-ri, Chuo-ku, Niigata 951-8510, Japan.}

Received: 14 September 2017 Accepted: 17 April 2018 Published online: 27 April 2018

\section{References}

1. Fry DE, Garrison RN, Heitsch RC, Calhoun K, Polk HC Jr. Determinants of death in patients with intraabdominal abscess. Surgery. 1980;88(4):517-23.

2. Wittmann DH. Intraabdominal infections-introduction. World J Surg. 1990;14(2):145-7.

3. Politano AD, Hranjec T, Rosenberger LH, Sawyer RG, Tache Leon CA. Differences in morbidity and mortality with percutaneous versus open surgical drainage of postoperative intra-abdominal infections: a review of 686 cases. Am Surg. 2011;77(7):862-7.

4. Kassi F, Dohan A, Soyer P, Vicaut E, Boudiaf M, Valleur P, Pocard M. Predictive factors for failure of percutaneous drainage of postoperative abscess after abdominal surgery. Am J Surg. 2014;207(6):915-21.

5. Ochsner A, Graves AM. Subphrenic abscess: an analysis of 3,372 collected and personal cases. Ann Surg. 1933;98(6):961-90.

6. Chaffanjon PC, Aubert A, Sandu C, Brichon PY. Transphrenic approach to subphrenic abscesses. Surgery. 2004;135(3):319-20.

7. Preece SR, Nelson RC, Bashir MR, Jaffe TA, Kim CY, Haystead CM. Safety of an intercostal approach for imaging-guided percutaneous drainage of subdiaphragmatic abscesses. AJR Am J Roentgenol. 2014;202(6):1349-54.

8. Seewald S, Brand B, Omar S, Yasuda I, Seitz U, Mendoza G, Holzmann T, Groth S, Thonke F, Soehendra N. EUS-guided drainage of subphrenic abscess. Gastrointest Endosc. 2004;59(4):578-80.
9. Goulet CJ. Endoscopic transgastric drainage of a subphrenic abscess. Gastrointest Endosc. 2007;65(4):733-5.

10. Piraka C, Shah RJ, Fukami N, Chathadi KV, Chen YK. EUS-guided transesophageal, transgastric, and transcolonic drainage of intra-abdominal fluid collections and abscesses. Gastrointest Endosc. 2009;70(4):786-92.

11. Tilara A, Gerdes $H$, Allen $P$, Jarnagin W, Kingham P, Fong Y, DeMatteo R, D'Angelica M, Schattner M. Endoscopic ultrasound-guided transmural drainage of postoperative pancreatic collections. J Am Coll Surg. 2014;218(1):33-40.

12. Holt B, Varadarajulu S. Endoscopic ultrasound-guided pelvic abscess drainage (with video). J. Hepatobiliary Pancreat. Sci. 2015;22(1):12-5.

13. Mandai $K$, Uno K, Yasuda K. Endoscopic ultrasound-guided drainage of postoperative intra-abdominal abscesses. World I Gastroenterol. 2015;21 (11):3402-8.

14. Mueller PR, Simeone JF, Butch RJ, Saini S, Stafford SA, Vici LG, Soto-Rivera C, Ferrucci JT Jr. Percutaneous drainage of subphrenic abscess: a review of 62 patients. AJR Am J Roentgenol. 1986;147(6):1237-40.

15. Hemming A, Davis NL, Robins RE. Surgical versus percutaneous drainage of intra-abdominal abscesses. Am J Surg. 1991;161(5):593-5.

16. Levison MA, Zeigler D. Correlation of APACHE II score, drainage technique and outcome in postoperative intra-abdominal abscess. Surg Gynecol Obstet. 1991;172(2):89-94.

17. Bufalari A, Giustozzi G, Moggi L. Postoperative intraabdominal abscesses: percutaneous versus surgical treatment. Acta Chir Belg. 1996;96(5):197-200.

18. Betsch A, Wiskirchen J, Trubenbach J, Manncke KH, Belka C, Claussen CD, Duda SH. CT-guided percutaneous drainage of intra-abdominal abscesses: APACHE III score stratification of 1-year results. Acute physiology, age, chronic health evaluation. Eur Radiol. 2002;12(12):2883-9.

19. McNicholas MM, Mueller PR, Lee MJ, Echeverri J, Gazelle GS, Boland GW, Dawson SL. Percutaneous drainage of subphrenic fluid collections that occur after splenectomy: efficacy and safety of transpleural versus extrapleural approach. AJR Am J Roentgenol. 1995;165(2):355-9.

20. Gervais DA, Brown SD, Connolly SA, Brec SL, Harisinghani MG, Mueller PR. Percutaneous imaging-guided abdominal and pelvic abscess drainage in children. Radiographics. 2004;24(3):737-54.

21. Neff CC, Mueller PR, Ferrucci JT Jr, Dawson SL, Wittenberg J, Simeone JF, Butch RJ, Papanicolaou N. Serious complications following transgression of the pleural space in drainage procedures. Radiology. 1984;152(2):335-41.

22. Giovannini M, Pesenti C, Rolland AL, Moutardier V, Delpero JR. Endoscopic ultrasound-guided drainage of pancreatic pseudocysts or pancreatic abscesses using a therapeutic echo endoscope. Endoscopy. 2001;33(6):473-7.

23. Varadarajulu S, Drelichman ER. Effectiveness of EUS in drainage of pelvic abscesses in 25 consecutive patients (with video). Gastrointest Endosc. 2009;70(6):1121-7.

24. Varadarajulu S, Wilcox CM, Christein JD. EUS-guided therapy for management of peripancreatic fluid collections after distal pancreatectomy in 20 consecutive patients. Gastrointest Endosc. 2011;74(2):418-23.

25. Ramesh J, Bang JY, Trevino J, Varadarajulu S. Comparison of outcomes between endoscopic ultrasound-guided transcolonic and transrectal drainage of abdominopelvic abscesses. J Gastroenterol Hepatol. 2013;28(4):620-5.

26. Lee DH, Cash BD, Womeldorph CM, Horwhat JD. Endoscopic therapy of a splenic abscess: definitive treatment via EUS-guided transgastric drainage. Gastrointest Endosc. 2006;64(4):631-4.

27. Noh SH, Park DH, Kim YR, Chun Y, Lee HC, Lee SO, Lee SS, Seo DW, Lee SK, Kim MH. EUS-guided drainage of hepatic abscesses not accessible to percutaneous drainage (with videos). Gastrointest Endosc. 2010;71(7):1314-9.

28. Zielinski MD, Cima RR, Baron TH. Endoscopic transgastric drainage of a postoperative intra-abdominal abscess after colon surgery. Gastrointest Endosc. 2010;71(4):880-2.

29. Kahaleh M, Shami VM, Conaway MR, Tokar J, Rockoff T, De La Rue SA, de Lange E, Bassignani M, Gay S, Adams RB, et al. Endoscopic ultrasound drainage of pancreatic pseudocyst: a prospective comparison with conventional endoscopic drainage. Endoscopy. 2006;38(4):355-9.

30. Hookey LC, Debroux S, Delhaye M, Arvanitakis M, Le Moine O, Deviere J. Endoscopic drainage of pancreatic-fluid collections in 116 patients: a comparison of etiologies, drainage techniques, and outcomes. Gastrointest Endosc. 2006;63(4):635-43.

31. Barthet M, Lamblin G, Gasmi M, Vitton V, Desjeux A, Grimaud JC. Clinical usefulness of a treatment algorithm for pancreatic pseudocysts. Gastrointest Endosc. 2008;67(2):245-52.

32. Varadarajulu S, Bang JY, Phadnis MA, Christein JD, Wilcox CM. Endoscopic transmural drainage of peripancreatic fluid collections: outcomes and predictors of treatment success in 211 consecutive patients. J Gastrointest Surg. 2011;15(11):2080-8. 
33. Siddiqui AA, Kowalski TE, Loren DE, Khalid A, Soomro A, Mazhar SM, Isby L, Kahaleh M, Karia K, Yoo J, et al. Fully covered self-expanding metal stents versus lumen-apposing fully covered self-expanding metal stent versus plastic stents for endoscopic drainage of pancreatic walled-off necrosis: clinical outcomes and success. Gastrointest Endosc. 2017;85(4):758-65.

34. Gornals JB, Loras C, Mast R, Botargues JM, Busquets J, Castellote J. Endoscopic ultrasound-guided transesophageal drainage of a mediastinal pancreatic pseudocyst using a novel lumen-apposing metal stent. Endoscopy. 2012;44 Suppl 2 UCTN:E211-2

35. Bohle W, Zoller WG. Mediastinitis after EUS-FNA in a patient with sarcoidosis - case report with endosonographic features and review of the literature. Zeitschrift fur Gastroenterologie. 2014;52(10):1171-4.

36. Okuno N, Hara K, Mizuno N, Hijioka S, Kuwahara T, Tajika M, Tanaka T, Ishihara M, Hirayama Y, Onishi S, Niwa Y. Risks of transesophageal endoscopic ultrasonography-guided biliary drainage. Gastrointest Interv. 2017;6(1):82-4

37. Morita S, Hara K, Suda T, Hijioka S, Okuno N, Kobayashi M, Terai S. The use of clip anchoring to ensure safe transgastric puncture during endoscopic ultrasound-guided transmural drainage. Endoscopy. 2017;49(7):E186-7.

38. Itoi T, Binmoeller KF, Shah J, Sofuni A, Itokawa F, Kurihara T, Tsuchiya T, Ishii K, Tsuji S, Ikeuchi N, et al. Clinical evaluation of a novel lumen-apposing metal stent for endosonography-guided pancreatic pseudocyst and gallbladder drainage (with videos). Gastrointest Endosc. 2012;75(4):870-6.

39. Khashab MA, Bukhari M, Baron TH, Nieto J, El Zein M, Chen Yl, Chavez YH, Ngamruengphong S, Alawad AS, Kumbhari V, et al. International multicenter comparative trial of endoscopic ultrasonography-guided gastroenterostomy versus surgical gastrojejunostomy for the treatment of malignant gastric outlet obstruction. Endosc Int Open. 2017:5(4):E275-e281.

\section{Ready to submit your research? Choose BMC and benefit from}

- fast, convenient online submission

- thorough peer review by experienced researchers in your field

- rapid publication on acceptance

- support for research data, including large and complex data types

- gold Open Access which fosters wider collaboration and increased citations

- maximum visibility for your research: over $100 \mathrm{M}$ website views per year 